
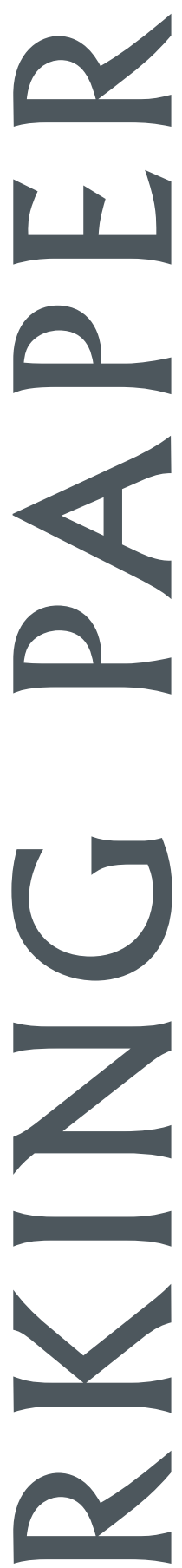

EAST-WEST CENTER 
The U.S. Congress established the East-West Center in 1960 to foster mutual understanding and cooperation among the governments and peoples of the Asia Pacific region including the United States. Funding for the Center comes from the U.S. government with additional support provided by private agencies, individuals, corporations, and Asian and Pacific governments.

East-West Center Working Papers are circulated for comment and to inform interested colleagues about work in progress at the Center.

For more information about the Center or to order publications, contact:

Publication Sales Office

East-West Center

1601 East-West Road

Honolulu, Hawaii 96848-1601

Telephone: 808-944-7145

Facsimile: 808-944-7376

Email: ewcbooks@EastWestCenter.org

Website: www.EastWestCenter.org 


\title{
Towards an Effective Implementation of CDM Projects in China
}

\author{
ZhongXiang Zhang
}

ZhongXiang Zhang is a Fellow in the Research Program at the East-West Center. He is also an adjunct professor of economics at both the Chinese Academy of Social Sciences and Peking University, Beijing, and an affiliate professor of economics at the University of Hawaii at Manoa. As the author of more than 120 publications in the fields of energy, climate and environmental economics, trade and the environment, public finance and macroeconomic modelling, he wrote the book The Economics of Energy Policy in China: Implications for Global Climate Change (Edward Elgar, 1998) and co-authored International Rules for Greenhouse Gas Emissions Trading (United Nations, 1999). Currently, he is serving on the editorial boards of seven international journals and one Chinese journal. He also served as an expert/consultant to many national and international organizations, served on many high level panels, presented research findings in more than 25 countries over the past six years, and has been included in Marquis Who's Who in Science and Engineering, Who's Who in the World, and Who's Who in America.

East-West Center Working Papers: Environmental Change, Vulnerability, and Governance Series is an unreviewed and unedited prepublication series reporting on research in progress. The views expressed are those of the authors and not necessarily those of the Center. Please direct orders and requests to the East-West Center's Publication Sales Office. The price for Working Papers is $\$ 3.00$ each plus shipping and handling. 


\section{Towards an Effective Implementation of CDM Projects in China}

\section{ZhongXiang Zhang ${ }^{1}$}

Research Program

East-West Center

1601 East-West Road

Honolulu, HI 96848-1601

USA

Tel: +1 8089447265

Fax: +1 8089447298

Email: ZhangZ@EastWestCenter.org

\footnotetext{
${ }^{1}$ ZhongXiang Zhang is a fellow at the East-West Center, Honolulu, USA. He is also an affiliate professor of economics at University of Hawaii at Manoa, and an adjunct professor of economics both at Centre for Environment and Development, Chinese Academy of Social Sciences, Beijing, China and at China Centre for Regional Economic Research, Peking University, Beijing, China. Currently, he is serving on the editorial boards of seven international journals (Climate Policy; Energy Policy; Energy and Environment; Environmental Management and Policy; Environmental Science and Policy; International Environmental Agreements; Mitigation and Adaptation Strategies for Global Change) and one Chinese journal. As the author of more than 120 publications in the fields of energy and environmental economics, trade and the environment, public finance and macroeconomic modelling, he wrote the book "The Economics of Energy Policy in China: Implications for Global Climate Change" (New Horizons in Environmental Economics Series, Edward Elgar, 1997) and co-authored "International Rules for Greenhouse Gas Emissions Trading" (United Nations, 1999). He served on many high level panels, served as an expert/consultant to many national and international organizations, and presented research findings in more than 25 countries over the past six years. He has been included in Marquis Who's Who in Science and Engineering, Who's Who in the World, and Who's Who in America.
} 


\begin{abstract}
With the already huge and growing amount of greenhouse gas emissions and a great deal of low-cost abatement options available, China is widely expected as the world's number one host country of clean development mechanism (CDM) projects. But, making this potential a reality represents a significant challenge for China, because there has been a general lack of awareness by both the Chinese government and business communities, institutional structure, and implementation strategy. This has raised great concern about China's ability to compete internationally for CDM projects and exploit fully its CDM potential.
\end{abstract}

This paper aims to address how CDM projects will be effectively implemented in China by examining the major CDM capacity building projects in China with bilateral and multilateral donors, the treatment of low-cost, non-priority CDM projects, and how a system for application, approval and implementation of CDM projects is to be set up in China and what roles the main institutional actors are going to play in the system. We conclude that these capacity building assistances, the establishment of streamlined and transparent CDM procedures and sound governance, and the lessons learned and experience gained from the implementation of the CDM project in Inner Mongolia and the two Prototype Carbon Fund (PCF)' projects will make China well positioned to take advantage of CDM opportunities. Moreover, in order to further exploit its CDM potential, we recommend that China should well define its sustainable development objective of the CDM, disseminate CDM knowledge to local authorities and project developers as sectorally and geographically wide as possible, and get at least two domestic legal entities accredited as designated operational entities. By taking these ongoing capacity building projects and the recommended actions, and gaining experience from real practice, it is thus expected that a much greater percentage of carbon credits is likely to come from CDM projects in China over the next several years as the Kyoto Protocol enters into force.

Keywords: Clean development mechanism; Capacity building; Charge/tax scheme; China; Sustainable development; Transaction costs 


\section{Introduction}

The Kyoto Protocol incorporates three flexibility mechanisms. Since then, attention has been focused on the establishment of rules and modalities governing the operation of these mechanisms. One of the biggest accomplishments in the recent three Conference of the Parties to the United Nations Framework Convention on Climate Change (UNFCCC) is that the rules and modalities have been agreed on to make the CDM fully operational. The CDM will channel private-sector investment into emissions abatement projects in developing countries. In this way, it will promote sustainable development in these countries while offering industrialized governments credits against their Kyoto targets.

Many economic modelling studies indicate that China is expected to emerge as the world's number one host country of CDM projects (e.g., Zhang, 1999, 2000, 2001, 2004a). But a general lack of awareness by both the Chinese government and business communities may cause China to not fully exploit its potential for CDM projects. The question is then how CDM projects will be effectively implemented there.

This paper aims to address this issue by examining the major CDM capacity building projects in China with bilateral and multilateral donors, the ways to deal with low-cost, non-priority CDM projects, and how a system for application, approval and implementation of CDM projects is to be set up in China and what roles the main institutional actors are going to play in the system. Our discussion will show that the development of sufficient capacity to initiate and undertake CDM projects and the sound institutional setting and implementation strategy has significant influence on effective 
implementation of CDM projects in China. This point is of high value to the Chinese government, because it underlines the importance for China to put a clear CDM policy, institutional setting and implementation strategy in place to encourage investors to develop CDM projects and thus fully exploit the potential of hosting CDM projects. The results of the study are also of particular interest to CDM investors, because they regard an effective implementation of CDM projects in China as a cost-effective means of obtaining certified emissions reductions (CERs) to meet their domestic emissions obligations in addition to the expansion of their business opportunities in the host country China.

The paper is structured as follows. Section 2 briefly discusses major international initiatives on CDM capacity building projects in China and their focuses, while Section 3 explains why the Dutch government withdrew a CDM capacity building study project with China. Section 4 outlines two plausible ways to deal with low-cost, non-priority CDM projects in China. Section 5 describes how a system for application, approval and implementation of CDM projects is to be set up in China and what roles the main institutional actors are going to play in the system. The paper ends with the main conclusions and policy recommendations.

\section{Major international initiatives on CDM capacity building projects in China and their focuses}


Asian countries including China and India have not rushed into the CDM process, as they are concerned about the quality of the CDM and the integrity of the Kyoto Protocol. ${ }^{2}$ This might be the desirable strategy when they have overly optimistic expectation for CDM investment. With the US withdrawal from the Kyoto Protocol, China gradually comes to realize that the size of the CDM market is much smaller than originally projected and that the CDM market is a competitive market. The issue then becomes getting something instead of nothing. Faced with weaker demand, Latin America is making the biggest strides in the CDM: having taken the lead in the CDM market as shown in Figure 1, the region has gained experience in actual projects and has raised awareness among local business (Zhang, 2004b). This clearly indicates whether host countries are able to create favourable conditions for CDM investors does make a difference. All this has led China to gradually recognize the importance of capacity building at national, local and enterprise levels to ensure that China is well positioned to take advantage of CDM opportunities. In the meantime, a growing number of international and bilateral donors are keen to support CDM capacity building in China because they expect great potential of the CDM in China and feel the significant need for China to gain more insight into the $\mathrm{CDM}$ and increase its capacity to initiate and undertake CDM projects. Table 1 briefly describes the major CDM capacity building projects in China. To harness potential synergies and minimize overlaps of these projects, the National Development and Reform Commission (NDRC) and the Ministry of Science and Technology (MOST) - the two leading Chinese ministries in charge of formulating and coordinating China's climate

\footnotetext{
${ }^{2}$ Cited in the Report of the Asia Meeting on Efficient Clean Development Mechanism Operations, organised by the UNDP and the World Bank, 1-3 April 2003, Kuala Lumpur, Malaysia.
} 
policy and actions, have exerted strong co-ordination to ensure that each of the projects has different focus. For example, the World Bank project focuses on the methodological aspects of the $\mathrm{CDM}$, the $\mathrm{ADB}$ project on small-scale $\mathrm{CDM}$ energy projects, the $\mathrm{C} 5$ project on an operational model and case studies in the areas of urban transportation and renewable energy, and the UNDP project on capacity building needs of industry and three CDM pilot projects in the areas of renewable energy, energy efficiency and coal bed methane. Clearly, China is attempting to make the best use of these capacity building projects to build domestic institution and capacity. If they are implemented effectively, China could get part of home work done with assistances of international and bilateral donors. This will lay the groundwork for the successful development and financing of CDM projects in China.

Figure 1 The location of project-based emissions reductions generated in $2002-\mathrm{Q3}$ 2003 (in million tons of $\mathrm{CO}_{2}$-equivalent)

Source: Lecocq and Capoor (2003).

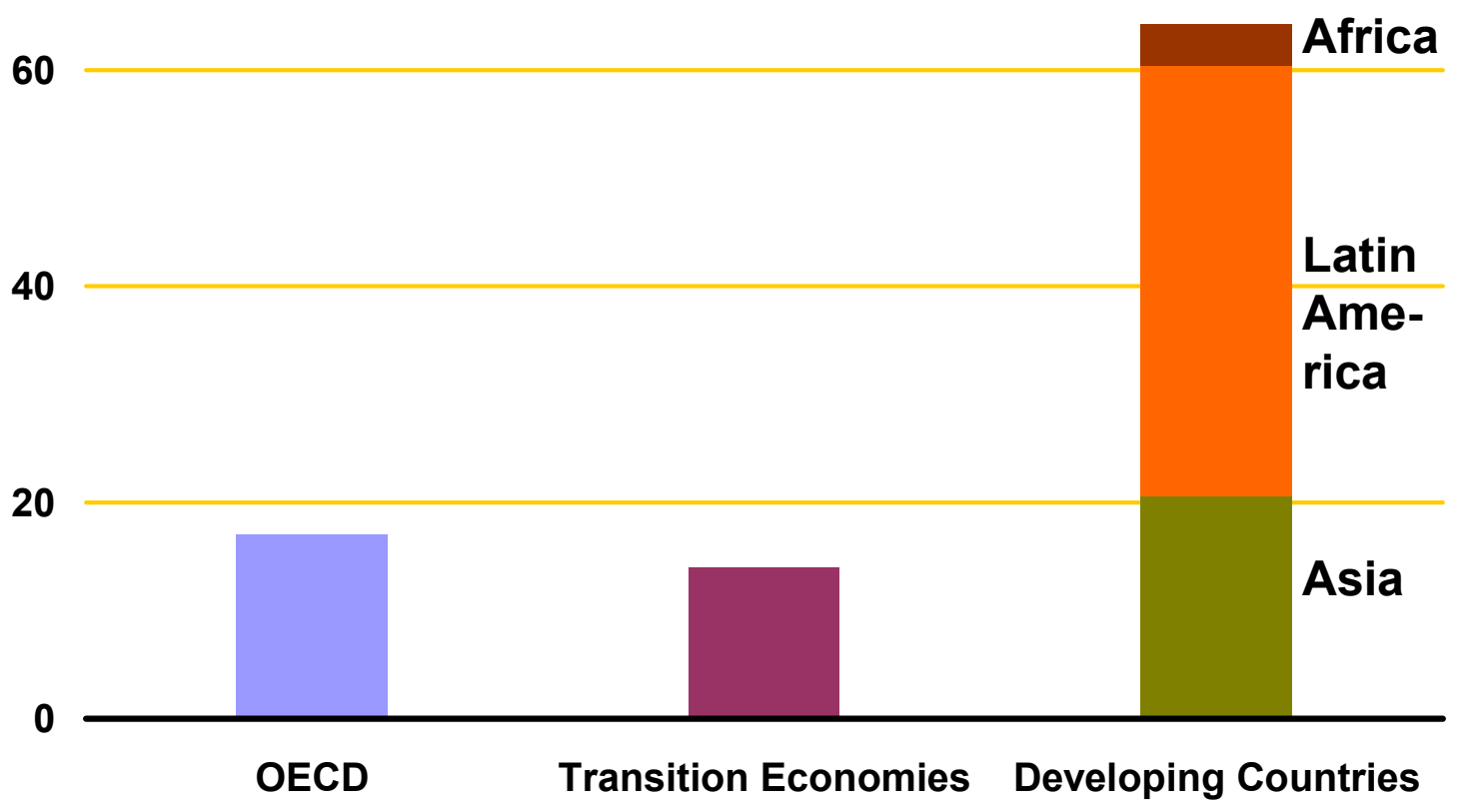


Table 1 Major CDM capacity building projects in China

\begin{tabular}{|c|c|c|c|}
\hline $\begin{array}{l}\text { Project title/ } \\
\text { Donors }\end{array}$ & $\begin{array}{l}\text { Project purposes/main } \\
\text { activities }\end{array}$ & $\begin{array}{l}\text { Donors' } \\
\text { contributions }\end{array}$ & Status/Duration \\
\hline $\begin{array}{l}\text { China CDM Study } \\
\text { - funded by the } \\
\text { World Bank, the } \\
\text { Swiss Government } \\
\text { and the German } \\
\text { Agency for } \\
\text { Technical } \\
\text { Cooperation (GTZ) }\end{array}$ & $\begin{array}{l}\text { 1) Address a series of } \\
\text { methodological and } \\
\text { technical issues for the } \\
\text { application of the CDM in } \\
\text { China } \\
\text { 2) Undertake six CDM } \\
\text { project case studies from } \\
\text { the power sector and } \\
\text { renewable energy field } \\
\text { 3) Analyze China's CDM } \\
\text { potential }\end{array}$ & US\$ 970,000 & $\begin{array}{l}\text { Draft final report } \\
\text { completed } \\
\text { November } 2003 \\
\text { Final report June } \\
2004\end{array}$ \\
\hline $\begin{array}{l}\text { Canada-China } \\
\text { Cooperation in } \\
\text { Climate Change } \\
\text { (C5) - Canada } \\
\text { project funded by } \\
\text { the Canadian } \\
\text { International } \\
\text { Development } \\
\text { Agency (CIDA) }\end{array}$ & $\begin{array}{l}\text { 1) Develop a CDM } \\
\text { operational model } \\
\text { 2) Undertake case studies } \\
\text { in the areas of urban } \\
\text { transportation - CNG buses } \\
\text { in Beijing, and renewable } \\
\text { energy - biomass } \\
\text { gasification in Guangdong } \\
\text { Province } \\
\text { 3) Carry out research study } \\
\text { on carbon sinks }\end{array}$ & C\$ 5 million & $\begin{array}{l}\text { June } 2002 \text { - June } \\
2004\end{array}$ \\
\hline $\begin{array}{l}\text { Opportunities for } \\
\text { the Clean } \\
\text { Development } \\
\text { Mechanism in the } \\
\text { Energy Sector - } \\
\text { ADB project } \\
\text { financed by } \\
\text { Canadian Co- } \\
\text { operation Fund for } \\
\text { Climate Change }\end{array}$ & $\begin{array}{l}\text { 1) Examine the } \\
\text { opportunities of the CDM } \\
\text { in the energy sector } \\
\text { 2) Develop handbooks of } \\
\text { small-scale CDM energy } \\
\text { projects } \\
\text { 3) Provide the PDDs of } \\
\text { four small-scale CDM } \\
\text { projects in Gansu and } \\
\text { Guangxi provinces } \\
\text { 4) Assess necessary } \\
\text { institutional framework at } \\
\text { national and provincial } \\
\text { levels to promote CDM } \\
\text { operation }\end{array}$ & US\$ 775,000 & $\begin{array}{l}\text { September } 2002 \\
\text { - August } 2003\end{array}$ \\
\hline Building Capacity & 1) Strengthen government's & US $\$ 1,458,000$ & November 2003 - \\
\hline
\end{tabular}

\footnotetext{
${ }^{3}$ In addition to the CDM, the Canadian project also includes components such as Awareness and Outreach; National Communications; and Impacts and Adaptation. For further information, see the $\mathrm{C} 5$ project's web site at: http://www.ec.gc.ca/etad/default.asp?lang=En\&n=2E25F028-11.
} 


\begin{tabular}{|c|c|c|c|}
\hline $\begin{array}{l}\text { Project title/ } \\
\text { Donors }\end{array}$ & $\begin{array}{l}\text { Project purposes/main } \\
\text { activities }\end{array}$ & $\begin{array}{l}\text { Donors' } \\
\text { contributions }\end{array}$ & Status/Duration \\
\hline $\begin{array}{l}\text { for the Clean } \\
\text { Development } \\
\text { Mechanism in } \\
\text { China - UNDP } \\
\text { project funded by } \\
\text { UN Foundation, } \\
\text { Italian Ministry for } \\
\text { Environment and } \\
\text { Territory and } \\
\text { Norwegian Agency } \\
\text { for Development } \\
\text { Cooperation } \\
\text { (NORAD) }\end{array}$ & $\begin{array}{l}\text { institutions ability to } \\
\text { implement procedures that } \\
\text { will enable Chinese } \\
\text { industry to gain smooth } \\
\text { approval for suitable CDM } \\
\text { projects } \\
\text { 2) Provide stakeholders } \\
\text { with the skills and } \\
\text { knowledge to enable CDM } \\
\text { projects to be developed in } \\
\text { China } \\
\text { 3) Prepare CDM pre- } \\
\text { feasibility studies and } \\
\text { implement three CDM pilot } \\
\text { projects in the areas of } \\
\text { renewable energy, energy } \\
\text { efficiency and coal bed } \\
\text { methane } \\
\text { 4) Establish an improved } \\
\text { CDM database and develop } \\
\text { website for information } \\
\text { dissemination }\end{array}$ & & November 2006 \\
\hline
\end{tabular}

Sources: ADB (2002); The Government of the PRC and UNDP (2003); Tsinghua University (2003); The Web Site of Ottawa-based Resource Futures International at: http://www.rfigroup.com.

\section{Why did the Dutch government withdraw a CDM capacity building study project}

\section{with China?}

It should be pointed out that not all international capacity building initiatives have been implemented in China as planned. The Netherlands had originally signed a project with the then State Development Planning Commission (SDPC) (the current National Development and Reform Commission) in April 2001 (Li, 2001), but the project was initially shelved and eventually withdrawn. Domestic bureaucratic hurdles between the then Ministry of Foreign Trade and Economic Co-operation (MOFTEC) and the then 
SDPC played a part for this. ${ }^{4}$ The MOFTEC is the government counterpart of the UNDP and other multilateral and bilateral development aid agencies in China. The CICETE (China International Center for Economic and Technical Exchange), which is affiliated with the MOFTEC, is the coordinating authority of the Chinese government for all the UNDP and other multilateral and bilateral development aid projects in China. Logically, the partnership agreement of this kind was supposed to be signed between the MOFTEC and the Netherlands, not between the SDPC and the Netherlands. The MOFTEC as the government counterpart may well perceive to be sidelined right from the outset. Regardless of this allegation, many observers (Lin et al., 2004) believe that the major reason for this was due to differences in opinion of the project focus. The Dutch side placed the main emphasis on capacity building of the enterprises and the industry associations (in the chemical, iron and steel sectors) in order to facilitate the identification of good energy projects and enable the enterprises to participate in international tenders. Therefore, the Dutch side wanted direct involvement of the Chinese experts in the industry associations. The Chinese government, however, preferred the Dutch project to work together with a Chinese university within the field of research. But the Dutch side saw that three donors already worked with that university on research capacity building, and questioned the additional value of doing similar project with it. ${ }^{5}$ In the mean time, the Dutch Ministry of Housing, Spatial Planning and the Environment (VROM) established the CERUPT (Certified Emission Reduction Unit Procurement Tender) ${ }^{6}$ program to directly purchase carbon credits through tender procedures. The initial CERUPT tenders

\footnotetext{
${ }^{4}$ Author' interviews in Beijing, January 2004.

${ }^{5}$ Author' interview in Beijing on 15 January 2004.

${ }^{6}$ For a description of the CERUPT program, see the web site at: www.carboncredits.nl.
} 
led project developers to submit 78 expressions of interest. The Dutch government has put a national system in place to have selected the 18 most promising projects in terms of cost-effectiveness and feasibility. Together, these projects are expected to deliver the total emissions reduction of over 16.5 million tons of $\mathrm{CO}_{2}$ equivalent (JIQ, 2003). Although only one project's baseline methodology has to date got approved of the 18 selected projects (JIQ, 2004) and the remaining selected projects are awaiting the acceptance of their baseline methodologies by the CDM Executive Board (EB), it seems that the Dutch government is very satisfied with the results from these tenders. To have had a good price (about $\$ 5$ per ton of $\mathrm{CO}_{2}$ equivalent) for the tons purchased is more than expected. ${ }^{7}$ In the end, a combination of the different priorities on both sides and the promising results from the CERUPT tenders resulted in the Dutch withdrawal of the project, and it is unlikely that the Dutch government will get involved in similar projects again in China. ${ }^{8}$

It should be pointed out that although the Chinese government did not has its way, a Chinese company - the Inner Mongolia Wind Power Corporation -, with assistance of the Chinese Renewable Energy Industries Association, was awarded a CDM project contract in 2003 by the Dutch government through the CERUPT program. ${ }^{9}$ Among the 18 selected projects, this Inner Mongolia Huitengxile Wind Farm Development Project is the first CDM project in China. With the projected overall wind power capacity of $34.5 \mathrm{MW}$,

\footnotetext{
${ }^{7}$ Comments by Tilly Zwartepoorte, Director, Department of Climate Change and Industry of the VROM at the International Conference on Climate Policy after Marrakech: Towards Global Participation, Honolulu, Hawaii, 4-6 September 2003 (Zhang, 2004b).

${ }^{8}$ Author' interview in Beijing on 15 January 2004.

9 “Chinese wind farm makes Kyoto profits from Dutch", Reuters, 14 March 2003, Available at: http://www.planetark.com/dailynewsstory.cfm?newsid=20156.
} 
the first stage of this CDM project involves installing nine turbines of $600 \mathrm{~kW}$ each, all of which were already up and running as of January 2002 (World Bank, 2004).$^{10}$ The crediting period of the CDM project is taken as 10 years up to 2013. According to the contract, the price of CERs to be paid is $€ 5.4$ per ton of $\mathrm{CO}_{2}$ equivalent. As shown in Table $2,{ }^{11}$ this price is closest to the maximum offering price of CERs for renewable energy projects under the CERUPT program. The total emission reductions over the tenyear crediting period are estimated to be 606,000 tons of $\mathrm{CO}_{2}$ equivalent (JIQ, 2003). Through undertaking this CDM project along with the two PCF projects, ${ }^{12}$ the local project developer will gain valuable experience through actual practice. In the meantime, these projects on their own will play the very important demonstration role in both increasing the outside investor's confidence on local project developers and triggering more CDM projects in China.

\footnotetext{
${ }^{10}$ Based on personal communication with Senter (the tendering authority for the CERUPT) on 25 May 2004, this project proponent just finalized the project design document (PDD). Hopefully, this PDD including the more authorized, project-specific information will be made publicly available after the CDM ED meeting in this June. ${ }^{11}$ As shown in Table 2, the offering prices of CERs under the Dutch CERUPT program are differentiated according to technology types. Renewable energy projects in general have been assigned with a premium price.

${ }^{12}$ At this moment, two PCF projects in China are under preparation: one on run-of-river hydropower to displace coal-fired power in Gansu Province, and another on coal bed methane capture and power generation in Shanxi Province. The PCF will invest US\$ 8.5 million in the hydropower project and receive the emissions reduction of 2 million tons of $\mathrm{CO}_{2}$ equivalent of the total project's emissions reduction of 3.7 million tons of $\mathrm{CO}_{2}$ equivalent (PCF, 2003). For the coal bed methane project, the PCF as one of the investors will contribute US\$ 12.75 million in return of 3 million tons of $\mathrm{CO}_{2}$ equivalent of the total project's emissions reduction of 29 million tons of $\mathrm{CO}_{2}$ equivalent (PCF, 2003). See Zhang (2004c) for further discussions on why China had initially hesitated to sign up as a host country of PCF projects, what has led China to endorse the PCF projects in the end, and the implications of the PCF's offering prices for the emerging global carbon market.
} 
Table 2 The maximum offering prices of CERs under the Dutch CERUPT program

\begin{tabular}{l|c}
\hline CDM project type & $\begin{array}{l}\text { Maximum offering prices of CERs under } \\
\text { the Dutch CERUPT program ( } € \text { per ton of } \\
\mathrm{CO}_{2} \text { equivalent) }\end{array}$ \\
\hline Renewable energy (excluding biomass) & 5.5 \\
Biomass energy (excluding waste) & 4.4 \\
Energy efficiency improvement & 4.4 \\
Fossil fuel switch and methane recovery & 3.3 \\
\hline
\end{tabular}

Source: Senter Internationaal (2001).

\section{The treatment of low-cost, non-priority projects like HFC type of CDM projects in China}

Project selection criteria are very important because what kinds of criteria are going to be set and what kinds of projects are given priority certainly impact the scope of CDM projects and the overall size of investment. Led by the NDRC, a set of interim provisions and regulations on the operation of CDM in China, including project selection criteria, have been prepared. The approval of these provisions and regulations, along with the establishment of the National CDM Project Board and the CDM Project Management Center to be discussed in the next section, was expected to happen by the end of 2002 , but has been delayed due to the restructuring of governmental organization. ${ }^{13}$ At the time of writing (May 2004), these interim provisions and regulations have not been made public. However, given that China is more concerned about local pollutants, logically, CDM projects that would also lead to reductions in local pollutants, for example, energy efficiency improvement projects and renewable energy projects, would be given priority in China. On the other hand, outside investors/donors would probably like to have a large

${ }^{13}$ Author' interview in Beijing on 14 January 2004. 
choice of the types of CDM projects. Thus, project selection criteria could represent one area where the interests of the Chinese government conflict with those of outside investors. Closely related to this is the issue of how the Chinese government is going to deal with those low-cost, non-priority projects like HFC type of CDM projects, which only have climate benefits but do not offer other social and environmental benefits to host countries. In my view, there are two options that China could take:

A) Remove such low-cost, non-priority projects like HFC type of CDM projects from the list of CDM projects and forbid the implementation of them in China. This option is too blunt.

B) Charge fees or impose taxes to endorse any project under the CDM. This will ensure that the cheaper options are not the only ones that get implemented in China. Charges/taxes could be differentiated, with no charge/tax on those CDM projects that are in line with China's national priorities and development needs.

Legally speaking, either of the above options is allowed under the Kyoto Protocol. The CDM is both a market mechanism and a development mechanism, and has the twin goals of combating the global climate change and promoting sustainable development. A market mechanism means that the CDM market would gravitate towards the lowest mitigation options as measured by carbon value alone. On the other hand, although international agreements like the Kyoto Protocol and Marrakech Accords specify what are allowed (e.g., sinks projects and unilateral projects), it is up to individual developing country governments to define the project eligibility criteria and facilitate implementation 
of priority projects that are in line with their national priorities and development need. ${ }^{14}$ In other words, individual governments still have flexibility in choices that fit best into their national circumstances. Although different choice would certainly impact the scope of CDM projects and the overall size of investment, either of the above options would enable the Chinese government to filter CDM projects, thus encouraging those CDM projects that promote both climate and sustainable development goals.

There are both advantages and disadvantages of promoting particularly favorable CDM projects through a charge/tax scheme. On the positive side, a charge/tax on certain types of CDM projects would direct CDM capital flows towards those projects with the high overlap possible with other social and environmental criteria. This will ensure that the CDM helps accelerate the Chinese economy to move along the more sustainable paths. On the negative side, China's ability to use the CDM to promote more costly, sustainable development projects over cheaper alternatives that offer less co-benefits will be determined by the price competition that develops on the international carbon market. This would limit the degree to which 1) the charge/tax is imposed on low-cost, nonpriority CDM projects and 2) more costly projects could be advanced as candidate investments.

\footnotetext{
${ }^{14}$ For example, at this time, China does not allow unilateral CDM projects without direct involvement from partners of industrialized countries. This is partly because unilateral CDM projects do not contain the element of technology transfer and have no additional up-front investments from industrialized country partners. Another consideration might be that unilateral CDM projects, if allowed, would lead to an increase of cheaper permits flooding the already weak demand market, which would do more harm to developing countries. Ultimately, you could accumulate huge amount of credits. Later, when negotiating future commitments, other countries could argue that you should take on and meet more stringent commitments because of the many accumulated credits.
} 
While the Kyoto Protocol provisions allow the differentiated treatment of CERs from different types of CDM projects, does it conflict with any WTO rule? This boils down to whether CERs are considered as products or services under the WTO. Because CERs will be traded internationally and will have an economic value, they can in economic terms be characterized as commodities. However, the domestic or international tradability of CERs does not change them into products or services for WTO purposes, because the terms "product" and "service" are legal terms that take on specific meanings in the context of the GATT (General Agreement on Tariffs and Trade) and the GATS (General Agreement on Trade in Services) (Werksman, 1999). Even if CERs themselves are neither products nor services under the WTO, then rules differentiating the sources of CERs are not covered by WTO disciplines. Thus, an individual country is free to treat the sources of CERs differently as long as such differential treatment is not based on ownership.

Currently, a charge/tax scheme is under discussion in China. In case China is determined to adopt a charge/tax scheme for the purpose of promoting particularly favorable CDM projects, the following design and implementation issues have to be considered prudently:

- On what basis and how much to charge under a charge/tax scheme?

- If charges are imposed, who will collect charges? If not by tax authorities, how to be coordinated with tax authorities in collecting and using charges? 
- How to treat developed regions and less-developed regions within China, and how to treat the area with more urgent need to protect the environment within the same region under a charge/tax scheme?

These issues are only partially on the agenda of the Chinese government departments concerned (Lu, 2004), but are very important because they are essential to the success of such a scheme. It is unlikely that such a scheme will commence until these issues are seriously addressed.

\section{The main institutional actors in the policymaking and implementation of CDM projects in China $^{15}$}

As early as February 1990, the National Coordination Committee on Climate Change (NCCCC) was established in China. This inter-ministerial coordinating body is the highest policymaking organ for climate policymaking in China. The body is to supervise and coordinate ministries and agencies in their efforts to address climate change. The NCCCC is responsible for deliberation and coordination of national climate strategy, including CDM-related policies, regulations and criteria. Because the NDRC is in charge of the national development plan and national project evaluation and because climate change may potentially have serious social and economic implications, the Climate Change Office - the executive office of the NCCCC, is situated in the NRDC's Department of Regional Economy and is responsible for routine work of the Committee.

\footnotetext{
${ }^{15}$ The expected functions of major institutions engaged in CDM-related policymaking and management in China are based on Gao and Li (2003) and Sun (2003).
} 
It is undisputed that the NDRC has played and will continue to play the leading role in formulating and coordinating China's overall climate policy and actions. ${ }^{16}$ The NDRC is the designated national authority (DNA) in China, and makes the final approval of the CDM projects in China. Because science and technology play a very important role in addressing climate change problem and the project mechanisms involve many technical issues, the MOST has involved in climate issues from the right beginning, and will continue to provide expertise on the technical aspects of the CDM. The MOST has a representative on the CDM Executive Board. For matters related to the UNFCCC and its subsidiary instruments (e.g., the Kyoto Protocol, the Marrakech Accords), the Ministry of Foreign Affairs (MFA) will continue to take the lead in the international climate negotiations.

\subsection{Institutional structure of the CDM management in China}

Transparent CDM procedures and sound governance will reduce transaction costs of the CDM projects and mobilize investment from the private sector. The Chinese government has set as priorities the establishment of the institutional structure and streamlined procedures to reduce transaction costs of the CDM operation in China. For this, the National CDM Project Board is to be set up under the NCCCC. The Board consists of seven ministries (the NDRC, the MOST, the MFA, the State Environmental Protection Agency, China Meteorological Administration, the Ministry of Finance, and the Ministry of Agriculture), and is co-chaired by the NDRC and the MOST. The main responsibilities

\footnotetext{
${ }^{16}$ This explains why the Chinese delegations to the Conference of the Parties to the UNFCCC are headed by the minister-level official from the NDRC. This makes the Chinese case different from the US case where the head is Under Secretary of US State Department.
} 
of the Board include developing regulations and procedures for the operation of CDM projects in China, providing guidance to the operation of the CDM Project Management Center (PMC), approving the CDM projects (in particular, examining an estimate of the CERs generated by the project) that have passed the pre-screening by the PMC, and reporting to the NCCCC the implementation and performance of the CDM projects and making recommendations to the NCCCC on how to solve the problems encountered in implementing CDM projects.

The CDM Project Management Center has yet to be established. The Center is to be subordinated by the National CDM Project Board. Situated in the NDRC, the Center is mandated to take responsibility for all practical aspects of managing the CDM process in China. It will mainly operate on the project level and will be not involved in policymaking. Specifically, the PMC will engage in the following main project-related functions:

- Accept the application of CDM projects

- Screen the candidate CDM projects

- Submit those CDM projects that have passed the initial review to the CDM Project Board

- Develop and maintain an information system for China's CDM projects, and make related information available for the public access

- Monitor, and provide support and advice in the implementation process 
- Assist the Board in identifying capacity building needs and undertake and/or facilitate CDM-specific capacity building activities

- Take on other responsibilities assigned by the Board

- Provide information and make recommendations to the Board on CDM-related issues.

The establishment and the authorized size of the PMC have yet to be approved by the Committee of the Central Organization Constructing. This approval has been delayed due to the restructuring of governmental organization. Prior to the operation of the PMC, the Climate Change Office takes the temporary responsibility.

\subsection{Application and approval procedures for CDM projects in China}

A CDM project consists of the general component and the CDM component. The general component is the part related to specific project construction. This part has to go through the existing application and approval procedures for conventional project construction. Before being approved, a newly built project is required to undergo an environmental impact assessment (EIA). This EIA ensures that the pollution control facilities are designed, built and put into operation simultaneously with the principal part of the new project (the so-called "three-synchronous"). At the moment, there are no additional requirements for the EIA of the CDM projects. But for the CDM component, the following application and approval procedures apply: 
- A domestic project developer prepares a project design document (PDD) of the CDM project and sends the PDD to the PMC for an approval.

- The PMC screens all the CDM projects, and submits those CDM projects that have passed the screening process to the Board.

- The Board will examine the CDM projects that have passed the screening process by the PMC, and submit those approved projects to the NDRC.

- In collaboration with the MOST and the MFA, the NDRC makes the final approval of the CDM projects, issues the approval letter on behalf of the government of China, and asks the PMC to put the approved projects on record.

- The project developer selects an appropriate designated operational entity (DOE) to undertake an independent evaluation of the PDD against the requirements of the CDM. If the proposed project is determined valid, the DOE submits a request for registration to the CDM Executive Board.

- The project developer reports to the PMC the status of the approval within 10 days after it being communicated from the CDM Executive Board.

\section{Conclusions and recommendations}

With the already huge and growing amount of greenhouse gas emissions and a great deal of low-cost abatement options available, China is widely expected as the world's number one host country of CDM projects. But, making this potential a reality represents a significant challenge for China, because there has been a general lack of awareness by both the Chinese government and business communities, institutional structure, and 
implementation strategy. This has raised great concern about China's ability to compete internationally for CDM projects and exploit fully its CDM potential.

Generally speaking, Asian countries have not rushed into the CDM process, as they are concerned about the quality of the CDM and the integrity of the Kyoto Protocol. In this regard, China is no exception. This might be the desirable strategy when they have overly optimistic expectation for CDM investment. With the US withdrawal from the Kyoto Protocol, China gradually comes to realize that the size of the CDM market is much smaller than originally projected and that the CDM market is a competitive market. This realistic expectation and the sense of urgency to gain real experience through learningby-doing, combined with positive development in international negotiations on the rules and modalities for governing the operation of the CDM, have led to a positive and determined attitude of China towards the CDM. At least the following two positive and encouraging development trends reflect China's increased participation.

First, realizing the significant need to gain more insight into the CDM and increase its capacity to initiate and undertake CDM projects, China is working with a growing number of international and bilateral donors on many CDM capacity building projects. To harness potential synergies and minimize overlaps of these projects, the Chinese government has exerted strong co-ordination to ensure that each of these projects has different focus and that all these projects together help build capacity needed at national, local and enterprise levels to ensure that China is well positioned to take advantage of CDM opportunities. In addition, China has endorsed the two PCF projects, and a Chinese 
company has been awarded a CDM project contract - the first CDM project in China through the Dutch CERUPT program, although the Chinese government did not has its way in hoping to translate the signed agreement with the Netherlands into a research capacity building project on the CDM. No doubt, undertaking these projects will provide China with much-needed, real learning and practice about baseline setting, project boundaries, monitoring and verification at project levels, these aspects that are most relevant to all prospective projects under the CDM but in which China has gained little experience in the AIJ (Activities Implemented Jointly) pilot phase. All capacity building projects, the CDM project in Inner Mongolia and the two PCF projects will help to disseminate CDM-related knowledge, programs and financing opportunities to various stakeholders in China, particularly in the energy sector, and will lay the groundwork for the successful development and financing of CDM projects there.

Second, China has prioritized the areas of the CDM investment, and is putting sound institutional structure and implementation strategy in place. This institutional building involves establishing the National CDM Project Board and the CDM Project Management Center and defining their responsibility and functions in the development of regulations and procedures and a system for application, approval and implementation of CDM projects. In so doing, the Chinese government has clearly attempted to have streamlined and transparent CDM procedures and sound governance of clearer lines of responsibility and functions. These efforts will ease domestic procedures for future CDM projects, and help to reduce transaction costs of CDM projects and make CDM projects in China more attractive to outside investors. It is fair to say that the CDM project in 
Inner Mongolia with the Netherlands and the two PCF projects with the World Bank, to some extent, have helped to speed up the institutional building process in China, although its official approval has been delayed somewhat due to the restructuring of the overall governmental organization in China. Moreover, as the PCF experience suggests, these projects on their own will play the very important demonstration role in both increasing the outside investor's confidence on local project developers and triggering more CDM projects in China.

In order to fully exploit the potential of the CDM, further steps need to be taken in China. They include but are not limited to the following three ones. First, given that private investors have complained that China's requirements for approving CDM in the light of sustainable development (SD) are very unclear, China should make it clear to outside investors what is meant by the SD objective of the CDM on China's national conditions. The Kyoto Protocol only provides the general principle, but it is up to each individual developing country government to define what is meant by whether a specific CDM project meets the sustainable development objective of that host country. Currently, conflicting views have been expressed from the different government departments in China. ${ }^{17}$ Some department indicates that China intends to develop a set of specific SD indicators in the future, which are to be used to evaluate whether an individual CDM project implemented in China meets the SD objective. By contrast, other department concerned says that there is no need to separately develop a set of specific SD indicators, because a CDM project, which has undergone the EIA and has met the "three-

${ }^{17}$ Author' interviews in Beijing, January 2004. 
synchronous" requirements, is considered to has met the SD objective. Doing so will only add additional burden on CDM developers. In order to facilitate the implementation of CDM projects, China should make its stance on this more clear to CDM developers in the future, whatever that is. In case China is determined to develop the criteria against which the SD objective of CDM projects is measured, a set of specific SD indicators must be well defined and practically workable. For those low-priority CDM projects on the SD ground, we suggest adopting an economic instrument to deal with them, rather than removing them from the list of CDM projects and forbidding the implementation of them in China.

Another important step is to further disseminate CDM knowledge to local authorities and project developers, and get them involved in the process of CDM rules and proceduressetting. Currently, the CDM capacity is strong centrally in China, with the central government departments concerned and a few Beijing-based research institutes gained vital expertise and improved knowledge on the CDM. Although the current capacity building projects with international and bilateral donors, the CDM project in Inner Mongolia and the two PCF projects will help to get local authorities and project developers familiarized with CDM-related knowledge, programs and financing opportunities, the scope of their involvement and their representations of sectors and regions are far from the point needed to fully exploit its CDM potential.

Third, the Chinese government, with assistances of international and bilateral donors, should support two domestic legal entities to apply for accreditation/designation as a DOE. The DOE under the CDM validates and subsequently requests registration of a 
proposed CDM project activity, verifies emission reduction of a registered CDM project activity, certifies as appropriate and requests the CDM EB to issue CERs accordingly. Thus, the DOE plays a very important role in a CDM project cycle. At the time of writing (May 2004), the CDM EB has approved two DOEs and is in the process of considering 22 applications. ${ }^{18}$ However, none of these applicants are from China. This means that CDM projects in China have to rely on the expensive services of foreign DOEs for validation, registration, verification and certification. This inevitably increases transaction costs of CDM projects. Thus, to foster the effective implementation of CDM projects in China, China has to get initially at least two domestic legal entities accredited as DOEs, although more domestic DOEs could be established later on as the demand for DOE services increases.

In conclusion, China has lagged behind Latin America regarding the awareness of the $\mathrm{CDM}$, the formulation of CDM policy, institutional set-up, private sector involvement in the CDM, and the volume of emissions reductions exchanged, but is catching up quickly as it undertakes with massive capacity building with international and bilateral donors and puts the sound institutional structure and implementation strategy in place. Clearly, these capacity building assistances, the establishment of streamlined and transparent $\mathrm{CDM}$ procedures and sound governance, and the lessons learned and experience gained from the implementation of the CDM project in Inner Mongolia and the two PCF projects will greatly enhance China's ability to internationally compete for CDM projects and effectively implement CDM projects. Moreover, in order to further exploit its CDM

\footnotetext{
${ }^{18}$ Information on DOEs and an exhaustive list of DOEs are available at the UNFCCC web site at: http://cdm.unfecc.int/DOE.
} 
potential as suggested by many economic modeling studies, China should make its SD objective of the CDM well defined, disseminate CDM knowledge to local authorities and project developers as sectorally and geographically wide as possible, and get at least two domestic legal entities accredited as DOEs. By taking these ongoing capacity building projects and the recommended actions, and gaining experience from real practice, it is thus expected that a much greater percentage of carbon credits is likely to come from CDM projects in China over the next several years as the Kyoto Protocol enters into force.

\section{Acknowledgments}

This paper has benefited from useful discussions with the colleagues at the following Beijing-based organizations: the Chinese Academy of Social Sciences, the National Development and Reform Commission, the Ministry of Science and Technology, the Royal Netherlands Embassy in China, and the UNDP-China. That said, the views expressed here are those of the author. The author bears sole responsibility for any errors and omissions that may remain.

\section{References}

Asian Development Bank (ADB, 2002), Technical Assistance to the People's Republic of China for Opportunities for the Clean Development Mechanism in the Energy Sector, TAR: PRC 35429, March, Manila. 
Gao, G.S. and Li, L.Y. (2003), Implementation and Management of the CDM, Energy of China, Vol. 25, No. 6, pp. 11-16.

Joint Implementation Quarterly (JIQ, 2003), CERUPT First Round Concluded, JIQ, Vol. 9, No. 1, p. 2.

Joint Implementation Quarterly (JIQ, 2004), CDM Methodologies Approval Status, JIQ, Vol. 10, No. 1, p.14.

Lecocq, F. and K. Capoor (2003), State and Trends of the Carbon Market 2003, December 1, Prototype Carbon Fund, The World Bank, Washington, DC.

Li, L. (2001), Sino-Dutch Co-op Enters New Era, China Daily, April 21, Beijing.

Lin, W., Heggelund, G., Tangen, K. and J. Li (2004), Efficient Implementation of CDM in China, Report Prepared for the Norwegian Ministry of Foreign Affairs, February 5, Beijing.

Lu, X.D. (2004), Clean Development Mechanism: An Update, PowerPoint Presentation at Energy Research Institute, the National Development and Reform Commission January 16, Beijing.

Prototype Carbon Fund (PCF, 2003), Annual Report 2003, The World Bank, Washington, DC.

Senter Internationaal (2001), Terms of Reference: CERUPT 2001, November 1, The Hague, Available at: http://www.senter.nl/sites/erupt/contents/i000008/tor_cerupt2001.doc.

Sun, C.H. (2003), Clean Development Mechanism - International Rules and China's Activities, PowerPoint Presentation at Canada-China Workshop on the CDM in China, September 3, Beijing. 
The Government of the People's Republic of China and United Nations Development Program (The Government of the PRC and UNDP, 2003), Building Capacity for the Clean Development Mechanism in China, CPR/01/H02.

Tsinghua University (2003), The Study on the Methodologies and its Application of Clean Development Mechanism in China, Draft Final Report Prepared for the World Bank, November, Beijing.

Werksman, J. (1999), Greenhouse Gas Emissions Trading and the WTO, Review of European Community and International Environmental Law, Vol. 8, No. 3, pp. 251-264.

World Bank (2004), Clean Development Mechanism: Thinking a Proactive and Sustainable Approach, June, Washington, DC.

Zhang, Z.X. (1999), Estimating the Size of the Potential Market for All Three Flexibility Mechanisms under the Kyoto Protocol, Prepared for the Asian Development Bank under Contract TA-5592-REG, Faculty of Law and Faculty of Economics, University of Groningen, The Netherlands.

Zhang, Z.X. (2000), Estimating the Size of the Potential Market for the Kyoto Flexibility Mechanisms, Weltwirtschaftliches Archiv - Review of World Economics, Vol. 136, No. 3, pp. 491-521.

Zhang, Z.X. (2001), An Assessment of the EU Proposal for Ceilings on the Use of Kyoto Flexibility Mechanisms, Ecological Economics, Vol. 37, No. 1, pp. 53-69.

Zhang, Z.X. (2004a), Meeting the Kyoto Targets: The Importance of Developing Country Participation, Journal of Policy Modeling, Vol. 26, No. 1, pp. 3-19. 
Zhang, Z.X. (2004b), Report on the International Conference on Climate Policy after Marrakech: Towards Global Participation, Honolulu, Hawaii, 4-6 September 2003, Prepared for the Dutch Ministry of Housing, Spatial Planning and the Environment, the Japanese Ministry of the Environment, Industrial Technology Research Institute (Hsinchu, Taiwan), and Institute for Global Environmental Strategies (Kanagawa, Japan), 86 pp.

Zhang, Z.X. (2004c), The World Bank's Prototype Carbon Fund and China, East-West Center Working Papers (Environmental Series) No. 60, May, Honolulu; Nota di Lavoro, Fondazione Eni Enrico Mattei, Milan, Italy. 